\title{
Sentinel node biopsy as an adjunct to limb salvage surgery for epithelioid sarcoma of the hand
}

\author{
Alex Seal ${ }^{1}$, Raymond Tse ${ }^{2}$, Bret Wehrli ${ }^{3}$, Alex Hammond ${ }^{4}$ and \\ Claire LF Temple*2
}

Address: ${ }^{1}$ University of British Columbia, Vancouver, British Columbia, Canada, ${ }^{2}$ Division of Plastic Surgery, University of Western Ontario, London, Ontario, Canada, ${ }^{3}$ Department of Pathology, University of Western Ontario, London, Ontario, Canada and ${ }^{4}$ Department of Radiation Oncology, London Region Cancer Centre, London, Ontario, Canada

Email: Alex Seal - aseal@interchange.ubc.ca; Raymond Tse - ray.tse@utoronto.ca; Bret Wehrli - Bret.Wehrli@lhsc.on.ca; Alex Hammond - alex.hammond@Ircc.on.ca; Claire LF Temple* - ctemple4@uwo.ca

* Corresponding author

\section{Published: 29 June 2005}

World Journal of Surgical Oncology 2005, 3:4I doi:10.1/86/1477-7819-3-

41

This article is available from: http://www.wjso.com/content/3///4I

(C) 2005 Seal et al; licensee BioMed Central Ltd.

This is an Open Access article distributed under the terms of the Creative Commons Attribution License (http://creativecommons.org/licenses/by/2.0), which permits unrestricted use, distribution, and reproduction in any medium, provided the original work is properly cited.
Received: 22 April 2005
Accepted: 29 June 2005

\begin{abstract}
Background: Epithelioid sarcomas of the hand are rare, high-grade tumors with a propensity for regional lymphatic spread approaching $40 \%$.

Case presentation: A 54-year-old male with an epithelioid sarcoma of the palm was treated with neoadjuvant radiation, wide excision, and two-stage reconstruction. Sentinel lymph node biopsy was used to stage the patient's axilla. Sentinel node biopsy results were negative. The patient has remained free of local, regional and distant disease for the follow-up time of 16 months.
\end{abstract}

Conclusion: The rarity of this tumor makes definitive conclusions difficult but SLN biopsy appears to be a useful adjunct in the treatment of these sarcomas.

\section{Background}

Epithelioid sarcoma is a rare, high-grade, soft tissue sarcoma. These tumors typically present on the extremities, in males who are 20 to 30 years of age. Overall 5 and 10 year survival rates are $70 \%$ and $42 \%$ respectively [1]. Epithelioid sarcoma is among a group of sarcomas with a propensity for regional lymphatic spread, with lymph node metastasis rates reported between $17 \%-80 \%$ [2-7]. Due to the risk of regional spread, sentinel lymph node biopsy (SLN) may be useful in the management of this tumor.

The success of SLN biopsy is based on the principle that the primary tumor drains to one or a few lymph nodes in the regional basin. Histopathological analysis of these sentinel nodes has been shown to reflect the histology of the entire lymphatic basin $[8,9]$. This approach is currently the least invasive and most accurate nodal staging procedure for breast cancer and melanoma $[10,11]$. However, SLN biopsy has not been thoroughly investigated for sarcoma.

We report a case of SLN biopsy in conjunction with limb salvage surgery and complex soft tissue, neurovascular, and staged tendon reconstruction for the management of an epithelioid sarcoma of the hand.

\section{Case presentation}

An otherwise healthy 54-year-old right-handed laborer presented with an eight-year history of a slowly enlarging 


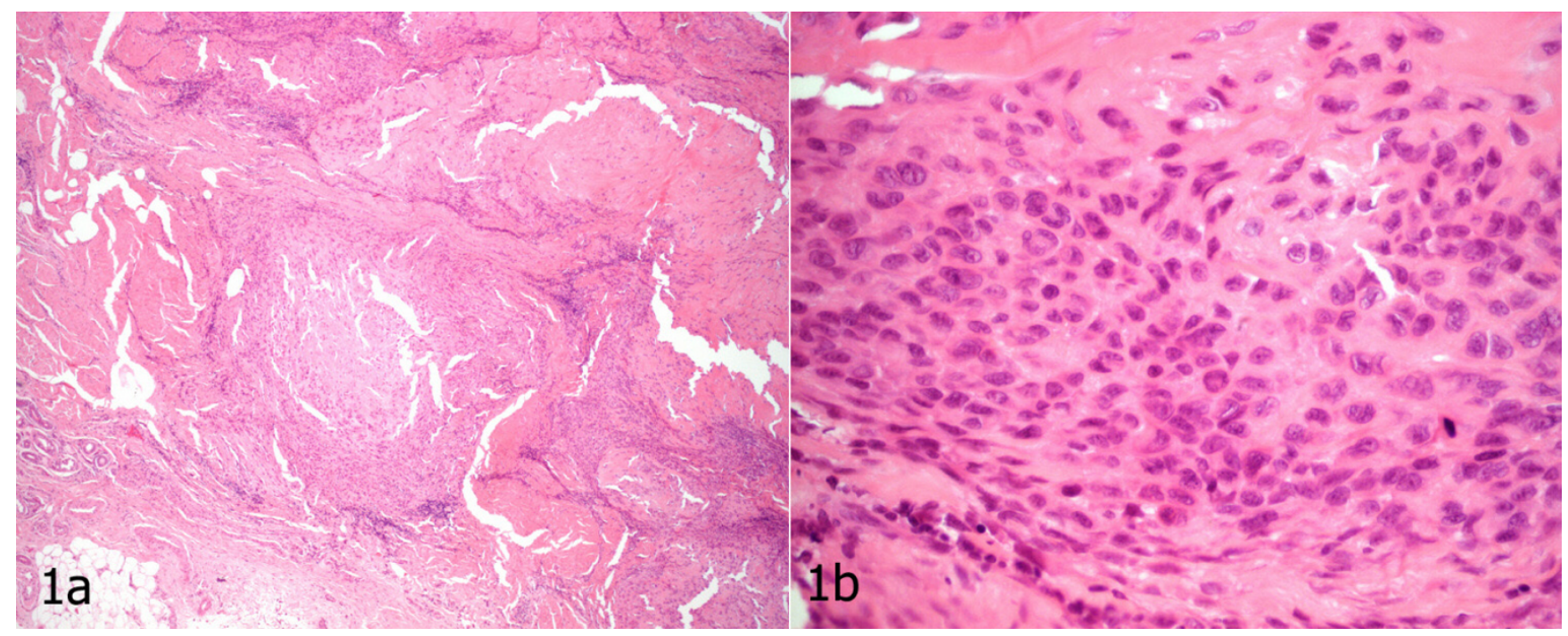

\section{Figure I}

Epithelioid sarcoma a) Conglomerate of tumor nodules with central necrosis mimicking a necrotizing granulomatous process at low magnification (hematoxylin and eosin $\times 4$ ) b) Epithelioid cells with abundant eosinophilic cytoplasm and prominent nuclear atypia, appreciated at high magnification (hematoxylin and eosin $\times 40$ ), distinguishes epithelioid sarcoma from its benign mimics. Note the presence of a mitotic figure.

"callus" in the palm of his right hand. He underwent excision at an outside institution. The operative note suggested that the tumor had the appearance of a sebaceous cyst with a large amount of surrounding tissue reaction. The neurovascular bundles were identified and preserved to the $4^{\text {th }}$ web space. An epithelioid sarcoma was identified upon histological analysis. Review of surgical pathology at our institution confirmed this diagnosis (Figure 1a and $1 \mathrm{~b}$ ). The excision was incomplete with tumor extending to several margins.

On examination, the patient had a transverse scar just proximal to the $4^{\text {th }}$ web space, with no palpable tumor. Neurovascular exam was normal, with normal range of motion of the associated digits. There were several small, palpable ipsilateral axillary nodes.

MRI of the right hand showed an ill-defined signal change within the palmar subcutaneous fat just deep to the surgical incision and distal to the $4^{\text {th }}$ and $5^{\text {th }}$ metacarpalphalangeal joints, consistent with post-surgical changes and scarring. No discrete soft tissue mass was seen to suggest gross tumor. Edema signal was seen in the distal aspect of the lumbrical muscle between the ring and small flexor tendons. The interosseous muscles appeared uninvolved. No osseous or articular abnormalities were identified.
Preoperative computerized tomography (CT) of the chest was negative. The axilla was reported as having benign appearing lymph nodes, fatty in nature with no evidence of necrosis.

The patient received preoperative radiation of 50 Gy in 25 fractions. CT simulation was used for planning the gross tumor volume (GTV) to ascertain the depth to be treated using electrons. A customized lead cutout was designed to avoid treating the full width of the hand and to avoid normal tissues ulnarly, radially and at depth. Bolus was placed over the palm to ensure adequate superficial skin and scar dose whilst ensuring the dose at depth covered the tumor and previous operative bed. A daily dose of 2 Gy was delivered to a total of 50 Gy over a five week period. Moderate erythema of the palm occurred which healed well post-treatment. There was no significant edema post-irradiation. Dysethesias were reported on the radial aspect of the small finger; however, two point discrimination remained normal.

Surgery was performed 6 weeks following completion of radiotherapy. Preoperative lymphoscintography (figure 2) identified a single "hot" ipsilateral axillary lymph node, which was successfully removed. Vital blue dye was not used, as it was felt that the blue stained tissues would worsen visibility for the wide excision. 


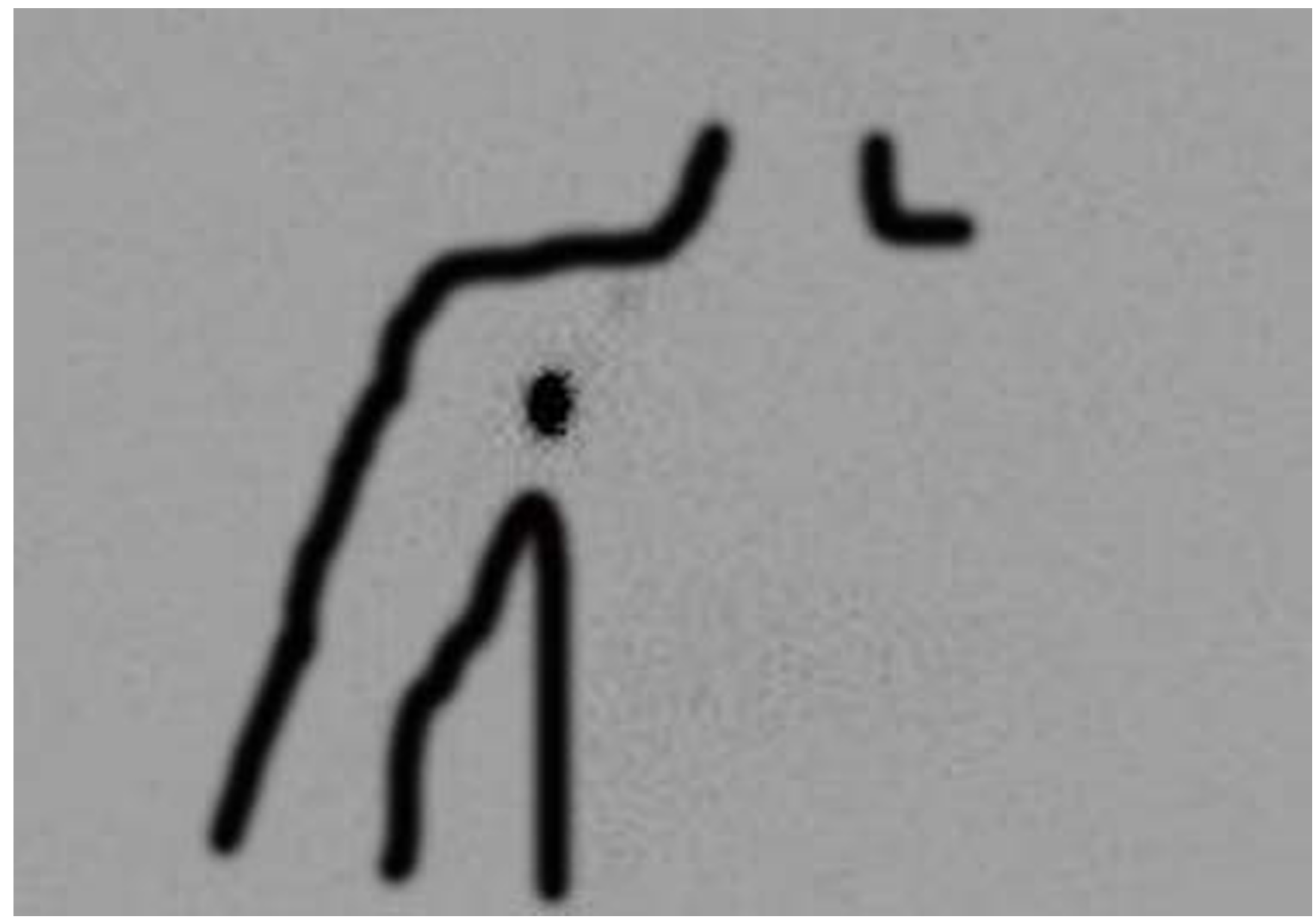

Figure 2

Preoperative lymphoscintigraphy identifies uptake of the radiolabelled tracer in a single axillary lymph node.

Wide, en bloc excision was carried out including palmar skin, subcutaneous fat, palmar fascia, flexor digitorum superficialis and profundus tendons (including their associated lumbricals) to the small and ring finger, and the neurovascular bundles to the $3^{\text {rd }}$ and $4^{\text {th }}$ web space. The excision plane was carried down to the level of the fascia of the interossei, along the volar shafts of the metacarpals (Figure 3).

Reconstruction included the placement of silicone rods to the small and ring fingers for the first part of a 2-stage flexor tendon reconstruction (Figure 4). Sural nerve grafts were placed to the small, ring and long finger. The small and ring fingers were revascularized from the superficial palmar arch with a Y-shaped vein graft harvested from the volar forearm.
The wound was then covered with a contralateral free radial forearm flap anastomosed to the radial artery and vena comitantes. The flap was innervated by neurorrhaphy of the lateral antebrachial cutaneous nerve in the flap to the palmar cutaneous branch of the median nerve. A small skin graft was used to cover the proximal pedicle to avoid compression.

Surgical pathology of the en bloc excision was negative for residual malignancy. Metastatic tumor was not identified within the sentinel lymph node following examination of multiple tissue levels of the node using both standard hematoxylin-eosin staining and immunohistochemical staining with antibodies against multiple cytokeratins and CD34, immunomarkers (frequently positive in epithelioid sarcoma). 


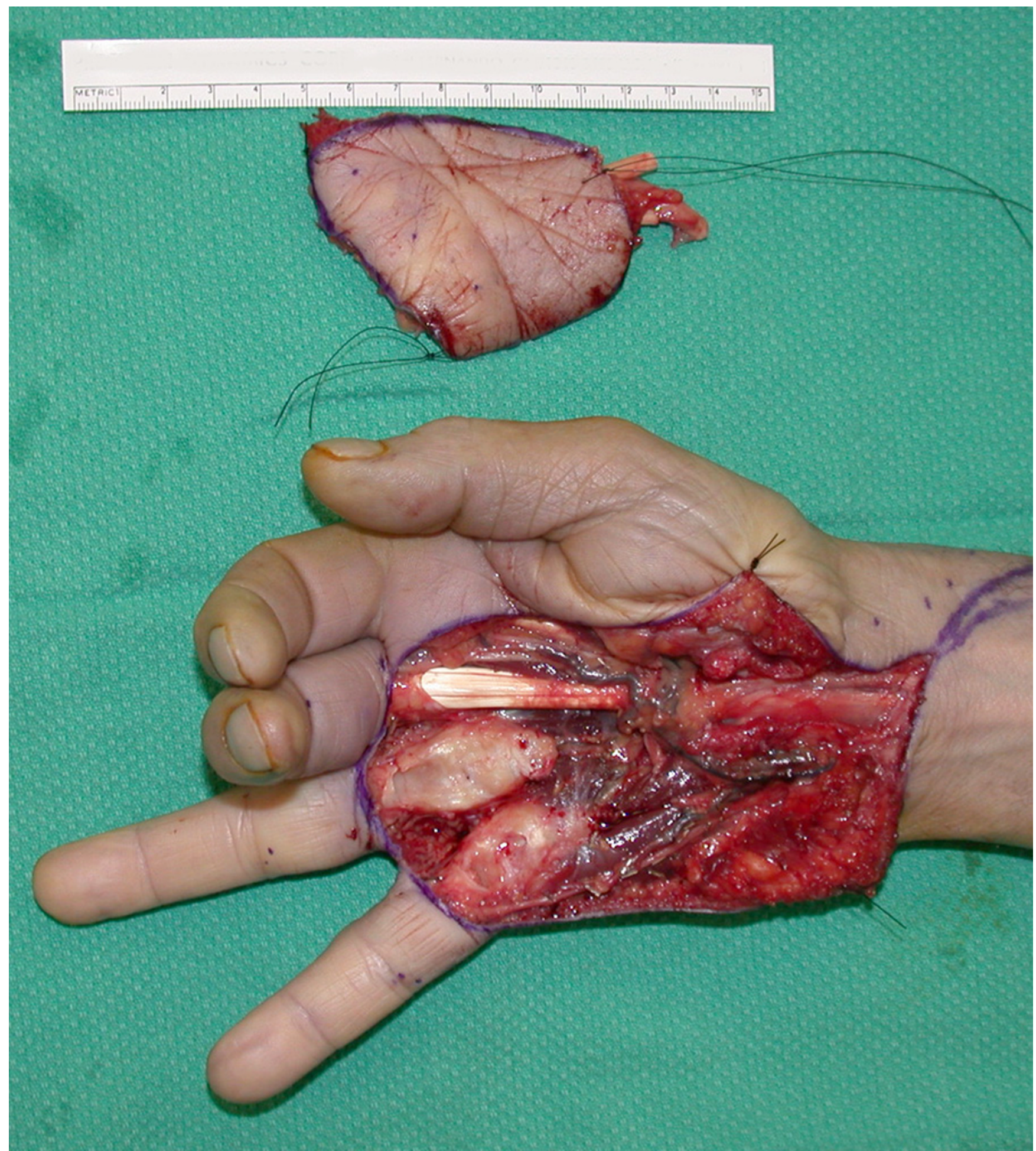

\section{Figure 3}

The appearance of the hand is shown following wide excision of skin, palmar fascia, flexor tendons, lumbricals, and neurovascular bundles. The small and ring fingers are postured in extension due to the absence of flexor tendons. The resection specimen is shown above. 


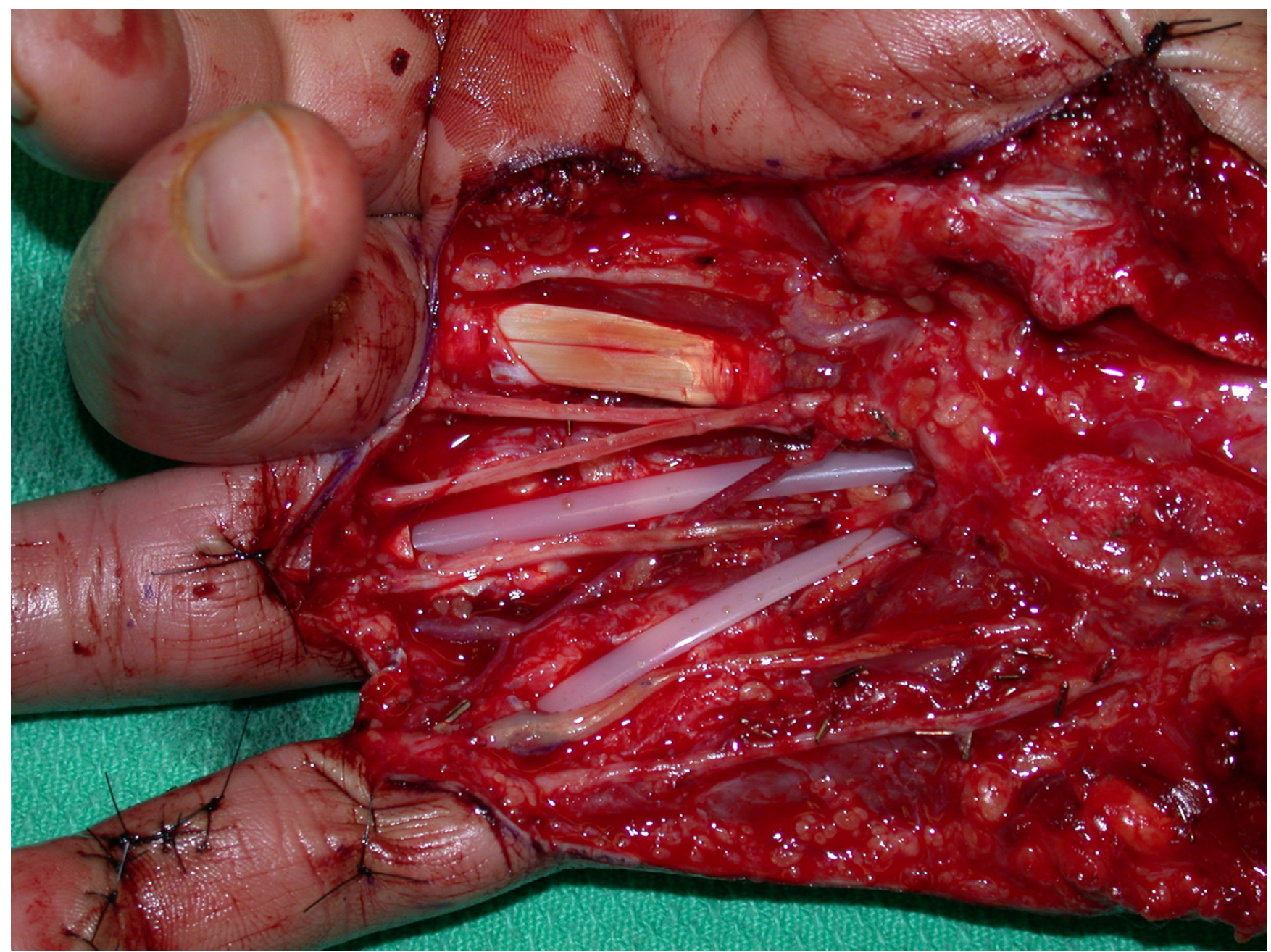

\section{Figure 4}

Sural nerve grafts, reversed Y-vein graft for digital revascularization of the small and ring fingers, and first-stage tendon reconstruction with silicone rod insertion is seen here. The construct was then covered with a contralateral free radial forearm flap.

At six months post-procedure, the radial forearm flap and donor site were well healed (Figure 5). The second-stage tendon reconstruction was undertaken by exchanging the silicone rods with extensor digitorum longus grafts from his $3^{\text {rd }}$ and $4^{\text {th }}$ toes for restoration of active finger flexion.

At 16 months post treatment, the patient remains free of local, regional and distant disease. He has regained acceptable hand function, with small and ring finger individual joint range of motion of 90 degrees at the metacarpal-phalangeal joints, 30 degrees at the proximal interphalyngeal joints, and 30 degrees at the distal interphalangeal joints (Figure 6). His moving two-point discrimination ranges from 5 to $7 \mathrm{~mm}$.

\section{Discussion}

Soft tissue sarcomas generally have a low incidence of regional lymph node metastasis (3-10\%) [2] and regional lymph node recurrence $(4-10 \%)[12,13]$. Standard treatment includes wide local excision with pre-or postoperative radiotherapy. Limb salvage surgery provides acceptable local control comparable to amputation, with no difference in survival. [13-20] Multivariate analysis has demonstrated that the presence of metastasis at presentation is the single most important risk factor for local recurrence. [4] This likely reflects the more aggressive biologic potential of tumors that metastasize early and are more likely to fail local treatment. 


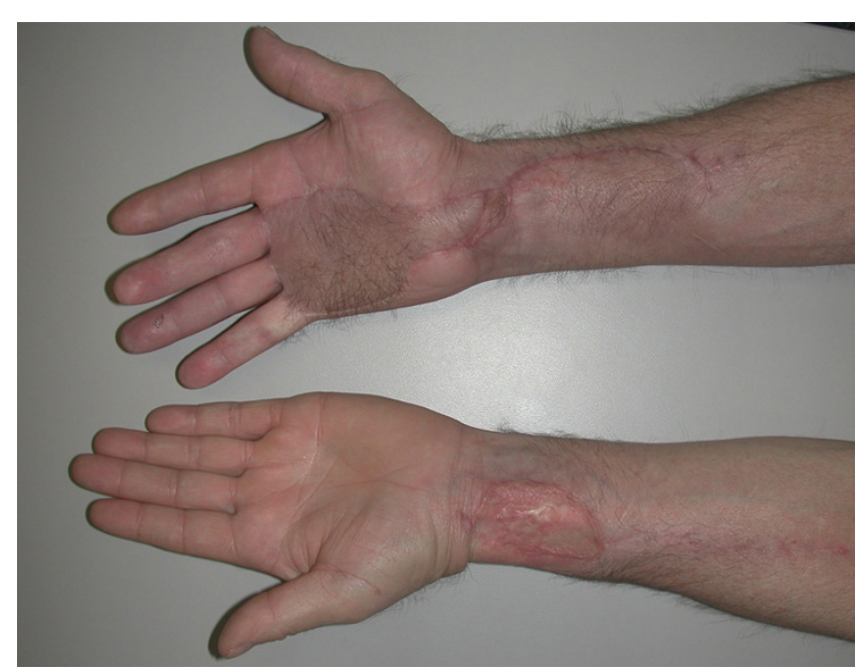

\section{Figure 5}

Prior to second-stage tendon grafting, the patient had a wellhealed radial forearm flap on his right palm. The donor site on the left forearm was satisfactory.

Treatment of sarcomas of the hand is particularly challenging due to the concentrated and intricate anatomy, which makes sparing of critical structures difficult. Furthermore, the majority of these tumors are extra-compartmental, violating multiple tissue planes. Microsurgical skill for complex vascular and neural repair is an integral part of the overall planning of these cases, since without sophisticated reconstruction, limb salvage for hand sarcomas is unlikely to be useful. Free flaps are commonly required to restore function as well as to facilitate primary healing. [14-18]

The propensity of epithelioid sarcoma for regional spread supports the role of minimally invasive regional node staging procedures for prognosis and treatment. SLN biopsy has dramatically changed the management of melanoma and breast cancer. It has been investigated in the mapping of other tumors including penile [21], lung [22], colon [23,24], upper GI tumors [25], gynecologic cancer $[26,27]$, thyroid cancer $[28,29]$, and squamous cell carcinoma of the head and neck $[7,30,31]$.

Given the success of the technique in other malignancies, it seems reasonable to apply SLN biopsy to soft tissue sarcomas of the extremity [8]. The role of SLN biopsy has not been extensively investigated in the treatment of sarcoma. In fact, there is only a single published report on its use in a child with rhabdomyosarcoma [9]. With the improved survival advantage of radical lymphadenectomy for clinically evident lymph node metastases from sarcoma, [4] accurate early detection of micrometastases may be important. Furthermore, patients with a negative sentinel lymph node biopsy for micrometastasis would be spared the morbidity of formal lymphadenectomy.

Identification of the sentinel node in sarcomas is more challenging than in breast and melanoma patients. Although successful identification of sentinel nodes exceeds 95\% when using both a vital blue dye and a nuclear tracer $[32,33]$, we avoided blue dye because it stain tissues and obscure planes. For resection in the hand, it is paramount to maintain precise visibility and a dyefree and bloodless field. Furthermore, when neoadjuvant radiotherapy is used, radiation-associated scarring of lymphatics could alter the accuracy of lymphatic mapping. Therefore, despite SLN biopsy, close follow-up of regional nodal basins is required. This includes assessment with clinical examination as well as with imaging such as highresolution ultrasound. Our particular patient required serial chest computed-tomography scans for follow-up of unrelated, non-specific lung nodules. This provided a concurrent, detailed, and serial assessment of the benign appearance of his operated axillary bed.

\section{Conclusion}

We report a case of epithelioid sarcoma of the hand successfully managed with a multi-disciplinary approach including neoadjuvant radiation, sentinel node biopsy and wide surgical excision. The rarity of this tumor makes definitive conclusions difficult but SLN biopsy appears to be a useful adjunct in the treatment of these sarcomas.

\section{Competing interests}

In the past five years we have not received reimbursements, fees, funding, or salary from an organization that may in any way gain or lose financially from the publication of this manuscript, either now or in the future. No such an organization financed this manuscript (including the article-processing charge).

- We do not hold any stocks or shares in an organization that may in any way gain or lose financially from the publication of this manuscript, either now or in the future.

- We do not hold nor are applying for any patents relating to the content of the manuscript. We have not received reimbursements, fees, funding, or salary from an organization that holds or has applied for patents relating to the content of the manuscript.

- We have no other financial competing interests.

We do not have any non-financial competing interests (political, personal, religious, academic, intellectual, commercial or any other) to declare in relation to this manuscript. 


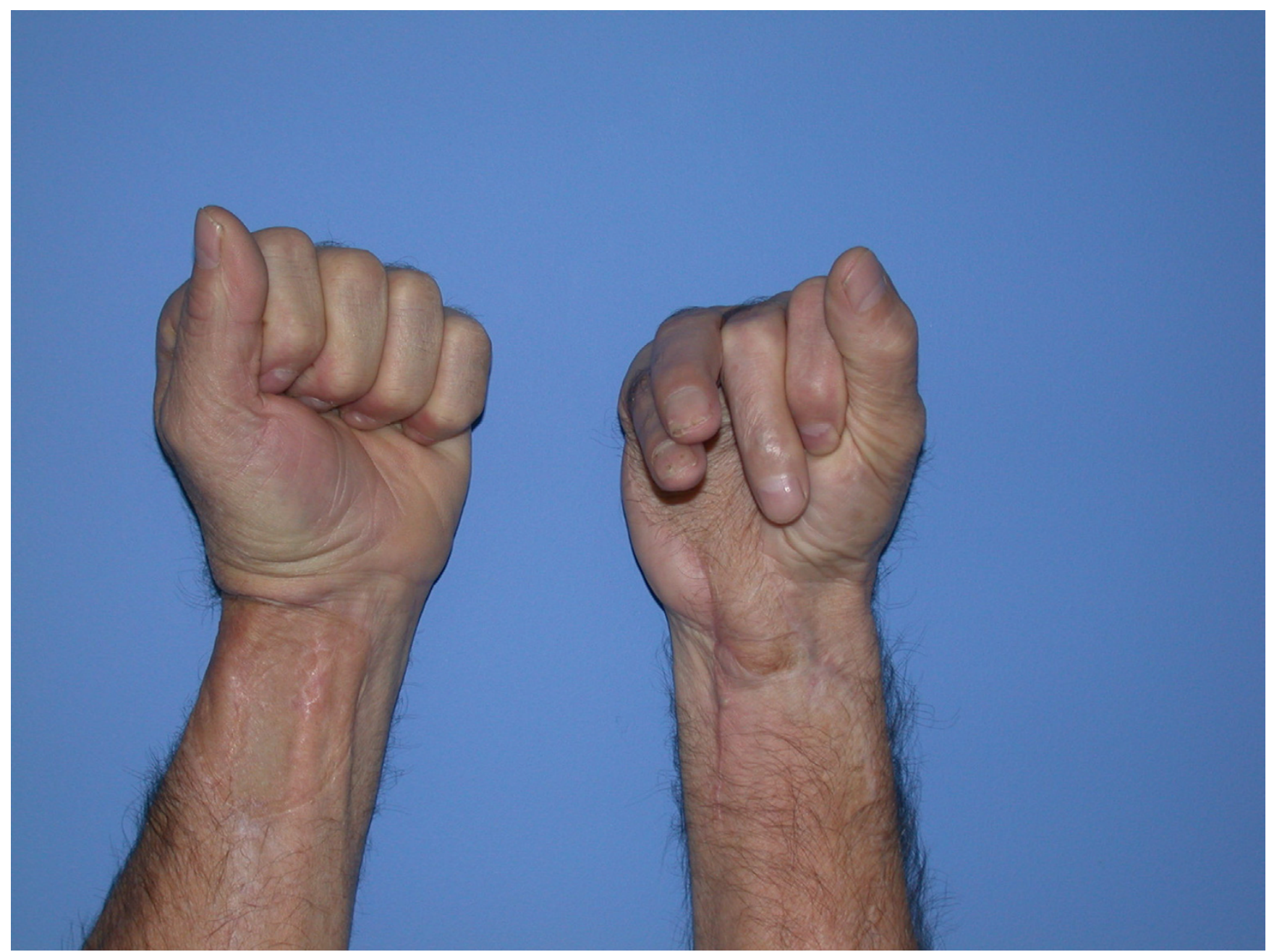

\section{Figure 6}

The final appearance of both hands after staged tendon grafting to the right ring and small fingers. There is functional restoration of composite finger flexion.

\section{Authors' contributions}

CT: Primary surgeon; report conception, writing, preparation and revision of manuscript, response to reviewers' questions, submission of manuscript, photographs

RT: First assistant surgeon; literature review, chart review, data collection, writing and preparation of manuscript

AS: Second assistant surgeon; literature review, chart review, data collection, writing and preparation of manuscript

AH: Radiation oncologist; chart review, writing and preparation of manuscript
BW: Pathologist; writing, preparation and revision of manuscript, histologic slide review, photographs

\section{Acknowledgements}

Patient consent was obtained for publication of this case report.

\section{References}

I. Spillane AJ, Thomas JM, Fisher C: Epithelioid sarcoma: the clinicopathological complexities of this rare soft tissue sarcoma. Ann Surg Oncol 2000, 7:2 18-225.

2. Skinner KA, Eilber FR: Soft tissue sarcoma nodal metastases: biologic significance and therapeutic considerations. Surg Oncol Clin N Am 1996, 5: 121-127.

3. Chase DR, Enzinger FM: Epithelioid sarcoma: diagnosis, prognostic indicators and treatment. Am J Surg Path 1985, 9:24|-263.

4. Fong Y, Coit DG, Woodruff JM, Brennan MF: Lymph node metastases from soft tissue sarcoma in adults. Analysis of data from a prospective database of 1772 sarcoma patients. Ann Surg 1993, 217:72-77. 
5. Mazeron J], Suit HD: Lymph node as sites of metastases from sarcomas of soft tissue. Cancer 1987, 60:1800-1808.

6. Weingrad DN, Rosenberg SA: Early lymphatic spread of osteogenic and soft-tissue sarcomas. Surgery |978, 84:23I-240.

7. Ross HM, Lewis JJ, Woodruff JM, Brennan MF: Epithelioid sarcoma: clinical behavior and prognostic factors of survival. Ann Surg Oncol 1997, 4:49|-495.

8. Blazer DG, Sabel MS, Sondak VK: Is there a role for sentinel lymph node biopsy in the management of sarcoma? Surg Oncol 2003, 1 2:201-206.

9. McMulkin HM, Yanchar NL, Fernandez CV, Giacomantonio C: Sentinel lymph node mapping and biopsy: a potentially valuable tool in the management of childhood extremity rhabdomyosarcoma. Pediatr Surg Int 2003, 19:453-456.

10. Giuliano AE, Dale PS, Turner RR, Morton DL, Evans SW, Krasne DL Improved axillary staging of breast cancer with sentinel lymphadenectomy. Ann Surg 1995, 222:394-399.

II. Clary BM, Brady MS, Lewis Jj, Coit DG: Sentinel lymph node biopsy in the management of patients with primary cutaneous melanoma; review of a large single institutional experience with an emphasis on recurrence. Ann Surg 200I, 233:250-258.

12. Potter DA, Glenn J, Kinsella T, Glatstein E, Lack EE, Restrepo C White DE, Seipp CA, Wesley R, Rosenberg SA: Patterns of recurrence in patients with high grade soft tissue sarcomas. J Clin Oncol 1985, 3:353-366.

13. Vezeridis MP, Moore R, Karakousis CP: Metastatic patterns in soft tissue sarcomas. Arch Surg 1983, 1 1 8:915-918.

14. Popov P, Tukiainen E, Asko-Seljavaara S, Huuhtanen R, Virolainen M Virkkunen $P$, Blomqvist C: Soft-tissue sarcomas of the upper extremity: surgical treatment and outcome. Plast Reconstr Surg 2004, I I 3:222-230. discussion

15. Lin PP, Guzel VB, Pisters PW, Zagars GK, Weber KL, Feig BW, Pollock RE, Yasko AW: Surgical management of soft tissue sarcomas of the hand and foot. Cancer 2002, 95:852-86I.

16. Lohman RF, Nabawi AS, Reece GP, Pollock RE, Evans GR: Soft tissue sarcoma of the upper extremity: A 5-year experience at two institutions emphasizing the role of soft tissue flap reconstruction. Cancer 2002, 94:2256-2264.

17. Doi K, Kuwata N, Kawakami F, Hattori Y, Otsuka K, Ihara K: Limbsparing surgery with reinnervated free-muscle transfer following radical excision of soft-tissue sarcoma in the extremity. Plast Reconstr Surg 1999, 104:1679-1687.

18. Athanasian EA: Malignant bone and soft-tissue sarcomas of the hand. I Am Society Surg Hand 2004, 4:60-72.

19. Whitworth PW, Pollock RE, Mansfield PF, Couture J, Romsdahl MM: Extremity epithelioid sarcoma. Arch Surg | 99|, I 26: | 485- I 489

20. Bray PW, Bell RS, Bowen CV, Davis A, O'Sullivan B: Limb salvage surgery and adjuvant radiotherapy for soft tissue sarcomas of the forearm and hand. J Hand Surg [Am] 1997, 22:495-503.

21. Cabanas RM: An approach to the treatment of penile carcinoma. Cancer 1977, 39:456-466.

22. Liptay MJ, Grondin SC, Fry WA, Pozdol C, Carson D, Knop C, Masters GA, Perlman RM, Watkin W: Intraoperative sentinel lymph node mapping in non-small-cell lung cancer improves detection of micrometastases. J Clin Oncol 2002, 20:1984-1988.

23. Esser S, Reilly WT, Riley LB, Eyvazzadeh C, Arcona S: The role of sentinel lymph node mapping in staging of colon and rectal cancer. Dis Colon Rectum 200I, 44:850-854. discussion 854-856

24. Bendavid Y, Latulippe JF, Younan RJ, Leclerc YE, Dube S, Heyen F, Morin M, Girard R, Bastien E, Ferreira J. Cerino M, Dube P: Phase I study on sentinel lymph node mapping in colon cancer: a preliminary report. J Surg Oncol 2002, 79:8I-84. Discussion 85

25. Aikou T, Higashi H, Natsugoe S, Hokita S, Baba M, Tako S: Can sentinel node navigation surgery reduce the extent of lymph node dissection in gastric cancer? Ann Surg Oncol 2001, 8:82S-85S.

26. Holub Z, Jabor A, Kliment L: Comparison of two procedures for sentinel lymph node detection in patients with endometrial cancer: a pilot study. Eur J Gynaecol Oncol 2002, 23:53-57.

27. Levenback C, Coleman RL, Burke TW, Bodurka-Bevers D, Wolf JK, Gershenson DM: Intraoperative lymphatic mapping and sentinel node identification with blue dye in patients with vulvar cancer. Gynecol Oncol 2002, 84:449-452.
28. Fukui Y, Yamakawa T, Taniki T, Numoto S, Miki H, Monden Y: Sentinel lymph node biopsy in patients with papillary thyroid carcinoma. Cancer 200I, 84:2868-2874.

29. Gallowitsch HJ, Mikosch P, Kresnik E, Starlinger M, Lind P: Lymphoscintigraphy and gamma probe-guided surgery in papillary thyroid carcinoma. Clin Nuc Med 1999, 24:744-746.

30. Altinyoller $\mathrm{H}$, Bergeroglu $\mathrm{U}$, Celen $\mathrm{O}$ : Lymphatic mapping and sentinel lymph node biopsy in squamous cell carcinoma of the lower lip. Eur J Surg Oncol 2002, 28:72-74.

3I. Wiseman SM, Loree TR, Hicks WL Jr, Rigual NR: Sentinel lymph node biopsy in SCC of the head and neck: a major advance in staging the N0 neck. Ear Nose Throat 2002, 81:156-160.

32. Clary BM, Brady MS, Lewis JJ, Coit DG: Sentinel lymph node biopsy in the management of patients with primary cutaneous melanoma; review of a large single institutional experience with an emphasis on recurrence. Ann Surg 200I, 233:250-258.

33. Jacobs IA, Chevinsky AH, Swayne LC, Magidson JG, Britto EJ, Smith TJ: Gamma probe-directed lymphatic mapping and sentinel lymphadenectomy in primary melanoma: reliability of the procedure and analysis of failures after long-term follow-up. J Surg Oncol 200I, 77:157-164.

Publish with BioMed Central and every scientist can read your work free of charge

"BioMed Central will be the most significant development for disseminating the results of biomedical research in our lifetime. "

Sir Paul Nurse, Cancer Research UK

Your research papers will be:

- available free of charge to the entire biomedical community

- peer reviewed and published immediately upon acceptance

- cited in PubMed and archived on PubMed Central

- yours - you keep the copyright

Submit your manuscript here:

http://www.biomedcentral.com/info/publishing_adv.asp

BiolMedcentral 